\title{
Preventing Damage by Updating Moisture Control Standards
}

\author{
Hartwig M. Künzel \\ Fraunhofer Institute for Building Physics, 83626 Valley, Germany, \\ Hartwig.Kuenzel@ibp.fraunhofer.de
}

\begin{abstract}
Despite progress in moisture control analysis, repairing moisture damage is still a considerable cost factor in the building sector. While there are many reasons for the lack of improvement during the last decades, inadequate moisture control standards are certainly also to blame. In many countries, interstitial condensation calculations according to Glaser are the sole means for assessing moisture control design, neglecting other important moisture loads such as driving rain, construction moisture and air infiltration. To overcome this lopsided focus on vapour diffusion, the update of the German moisture control standard has restricted the applicability of the Glaser method and introduced a normative Annex on performance evaluation by hygrothermal simulation. Recently, a new project has started to develop advanced models helping to evaluate the simulation results. Currently, it is already possible to assess the risk of mould growth, rot, and critical moisture accumulation by methods referred to in this standards. Also addressed in the standard is the selection of critical indoor and outdoor boundary conditions. Thus, it is officially encouraged to perform hygrothermal simulation, giving architects and engineers the chance to design more moisture tolerant and ultimately more durable constructions. Considering the necessity to reduce the carbon footprint of buildings, the application of hygrothermal simulation provides the opportunity to use more innovative renewable and recycled materials that could not adequately be judged by the Glaser method. Another benefit presents the analysis of construction resilience in case of natural disaster such as flooding or extreme rain events.
\end{abstract}

Keywords: Moisture Control Standard, Hygrothermal Simulation, Moisture Tolerance, Building Resilience, Damage Prevention.

\section{Introduction}

Moisture in the building structure impairs thermal performance and accelerates ageing and degradation. Therefore, moisture control has always been an issue for architects and engineers. Despite an improvement in construction quality, moisture problems have not diminished accordingly. This may partly be due to increasing energy savings requirements. More insulation and better air-tightness have resulted in lower temperatures at the exterior layers of the building envelope and higher indoor humidity. This increases the risk of interstitial condensation and reduces the drying potential. The high number of moisture related building failure also demonstrates that traditional condensation control and the steady-state tools to evaluate vapour diffusion are not sufficient to account for all relevant moisture loads. Additionally, natural disaster with torrential rain and flooding will become more frequent which means more risk for moisture susceptible but environmental friendly renewable materials. However, adequate moisture control design can help to prevent problems even in the most energy efficient structures. The necessary design tools are there, but they have to be applied the right way. While it is fair to assume that a building has been erected according to best practice, a perfect seal against water, vapour or air entry is difficult to achieve. Therefore, the consideration of 
imperfections should be part of moisture control assessments.

Hygrothermal simulation offers an opportunity to meet the current challenges if the underlying models allow for the fact that no building component is perfectly sealed and envelope leaks and other flaws are always built-in or may eventually occur during the building's service life. New approaches have been developed to account for rainwater penetration and indoor air infiltration. This paper summarizes these approaches and shows examples of standards and guidelines that have started to integrate them into the moisture control assessment process.

\section{Moisture Control Design Standards and Guidelines}

In the past, moisture control meant for most practitioners steady state vapour diffusion calculations - often called dew-point or "Glaser" calculations - that were performed to determine whether there is a risk of harmful interstitial condensation in the building assembly during the heating season. However, due to numerous simplifications the results of these calculations may be misleading especially when short-term loads such as solar vapour drive or rainwater absorption may have an impact. A steady-state calculation also means that all storage effects are neglected. This penalizes materials with moisture storage capacity, such as renewable insulation materials, because it assumes the formation of condensation where in real life only the sorption moisture content is slightly increased. There are actually many more drawbacks of employing dew-point calculations for moisture control design which lead to the following statement in

method is not recommer assemblies. ASHRAE ST

simesign purposes."

simulation tools.

To arrive at comparable results pertinent app
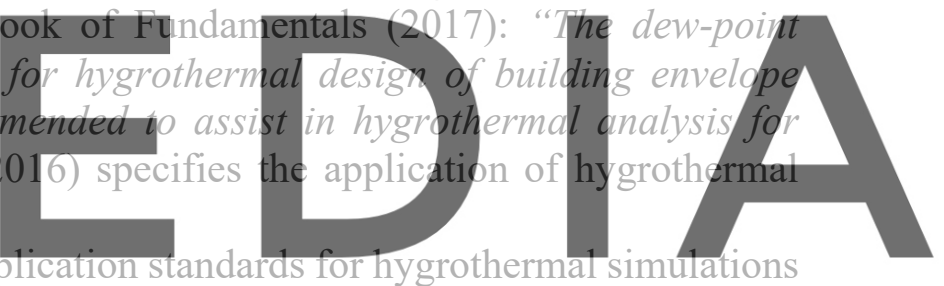

have been developed which are under continuous revision in order to accommodate new

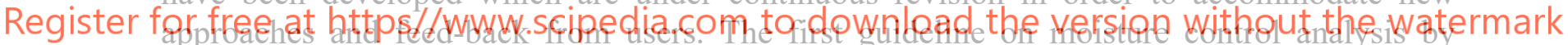

hygrothermal simulation was issued in 2002 by the WTA, an association dealing with preservation and renovation of heritage constructions and rehabilitation of the building stock (WTA 6-2 2002). Five years later the European Standard EN 15026 (2007) which is largely based on the WTA guideline was published. However, both documents did not contain any information on how to deal with small defects in the building envelope. Parallel to the standard work in Europe a slightly more comprehensive standard on moisture control design has been developed in North-America (ANSI/ASHRAE Standard 160 from 2009). As a result of numerous damage cases linked to rainwater penetration into constructions with rendered facades (Cheple and Huelman 2000), this standard has been the first that proposed the consideration of the effects of small leaks in the exterior finish of exposed walls.

\subsection{Updated Version of the Hygrothermal Simulation Guideline WTA 6-2}

Since the original version of the WTA 6-2 guideline served as blueprint for the European Standard 15026 (2007) and the updated version from 2014 has been referenced by the German Standard on moisture control design DIN 4108-3 (2018), the new items in this guideline will be described here briefly. Compared to the version from 2002 the WTA 6-2 (2014) allows the 
consideration of imperfections in the building envelope by simplified models. It also shows a way of dealing with ventilated cavities in a one-dimensional way and contains some new information concerning boundary conditions. The new version recognizes the problem of determining the material properties as accurately as possible for the intended use by a chart that recommends the test method as function of moisture range. This issue has come up in the context of capillary active insulation materials. These materials are rather vapour permeable, however, they are supposed to prevent condensation at the cold side by compensating the diffusion flux with an opposed liquid flux. This means, liquid transport in capillary active insulation materials has to achieve a considerable magnitude well below $100 \% \mathrm{RH}$. Most of the currently employed methods have been designed to determine liquid transport properties in the high moisture range, i.e. when the majority of capillaries are filled with water. However, these methods turned out to be inappropriate for the accurate determination of liquid transport in the hygroscopic range. Therefore, a new method has been developed by Binder et al. (2013) that determines the properties of interior insulation materials under the boundary conditions close to the real situation in practice application.

From a moisture safety point of view, however, the most important improvement is the introduction of simplified models to account for unavoidable rainwater and indoor air leakage into the building assembly. These models have been designed for one-dimensional simulations with the aim to quantify the moisture impacts of imperfections in the building envelope without dealing with the complex 3D phenomena that are assumed to happen in reality. Thus, these models are of limited validity and may work well for some construction types but may not be transferable to others. This may seem unfortunate; however, not envloying the models
described below, may be even more risky. Numerous failures have proven that perfedty
installed building assemblies without any leaks belongs to the realm of fiction. Nevertheless, it
is absolutely feasible to reduce the potential leaks to a level that will not do any harn to a
moisture tolerant construction. The application of the following model assumptions will help to design such moisture tolerant building assemblies.

Register for free at https//www.scipedia.com to download the version without the watermark 2.1.1 Rainwater penetration through imperfection in the exterior finish

As already mentioned the American moisture control standard ANSI/ASHRAE 160 (2016) proposes the consideration of small rainwater leaks through the exterior finish which may result from gaps or cracks at joints and connections. It states: "In the absence of specific fullscale test methods and data for the as-built exterior wall system being considered, the default value for water penetration through the exterior surface shall be $1 \%$ of the water reaching that exterior surface. The deposit site for the water shall be the exterior surface of the water-resistive barrier. If a water-resistive barrier is not provided, then the deposit site shall be described and a technical rationale for its selection shall be provided." In the case of ETICS (external wall insulation systems) on load bearing masonry walls the rainwater deposit site is likely to be the surface of the masonry beneath the insulation (see Figure 1).

It is obvious that neither the leaks nor the wind driven rain exposure are evenly distributed over the building envelope. But the standard committee chose this simple one-dimensional approach as a method to consider the effects of complex bulk water penetration phenomena observed in practice. The rainwater leakage rate proposed in the standard is not meant to be a worst case scenario. It is not based on field test results but on hygrothermal simulations 
(Desjarlais et al. 2001) that showed that more than $1 \%$ of rainwater penetration may be detrimental for a large portion of existing wooden wall structures. A recent literature review (Van Den Bossche et al. 2011), analysing data of leakage rates measured on different wall structures, confirmed the appropriateness of the "1\% leakage" in ANSI/ASHRAE Standard 160. Therefore the rationale of this standard was also adopted for the new WTA 6-2 (2014) guideline.

\section{$1 \%$ rainwater penetration}

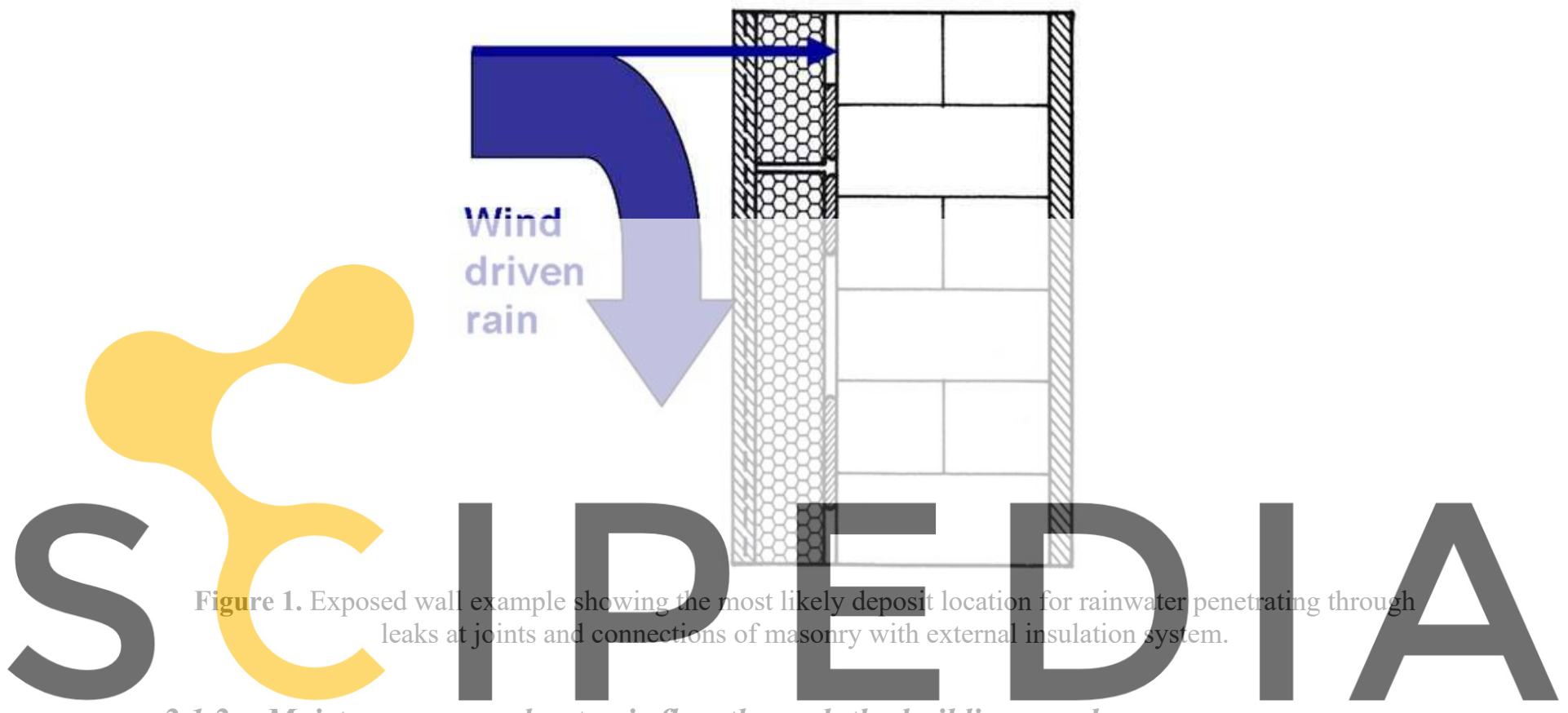

2.1.2 Moisture sources due to air flow through the building envelope

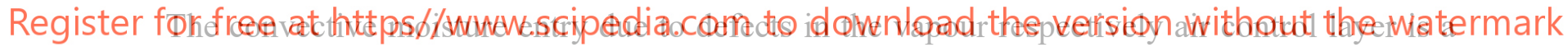
multidimensional effect, which cannot be captured directly by one-dimensional calculation. However, also the application of multidimensional simulation tools hardly solves the problem, because the exact configuration of leakages is generally unknown and the complexity of relevant flow paths is exceeding the capacity of most models. Therefore it has been decided to choose an approach that doesn't simulate the flow itself, but concentrates on the effects of vapour convection and subsequent condensation by introducing a moisture source inside the construction.

Based on experimental results from TenWolde et al. (1989), a simplified model to quantify the moisture sources due to vapour flow through the building envelope has been developed and checked for plausibility (e.g. Künzel et al. 2011). The model assumes that vapour contained in the indoor air, penetrating the envelope via so-called moisture leaks, condenses at the cold side of the insulation (see Figure 2). In contrast to energy leaks where the air remains warm because it flows in a short way from the room towards the outside, moisture leaks are small and tortuous channels where the air flow is slow and cools down within the flow path. These "moisture leaks" probably represent less than $10 \%$ of all leaks in the building envelope. The position of the condensation plane has to be selected by the user. Its temperature, governed by the transient 
boundary conditions, is simulated without taking the latent heat of condensation into account. The right choice of this position depends on the construction. It must be cold enough for condensation to occur and it must be easily accessible for the indoor air that has penetrated the interior lining or air barrier. Examples are the exterior sheathing of wood frame walls or roofs and the interface between the interior insulation and the original wall after thermal retrofits of plastered masonry structures. The convective moisture source is equal to the amount of condensate that forms when the indoor air temperature is cooled down to the temperature of the selected condensation plane in the building assembly. Any increase in sorption water content that could occur in reality by the temperature drop is neglected. In order to remain on the safe side convective drying is excluded, i.e. the moisture accumulated by air convection can only dry out by vapour diffusion or liquid transport.

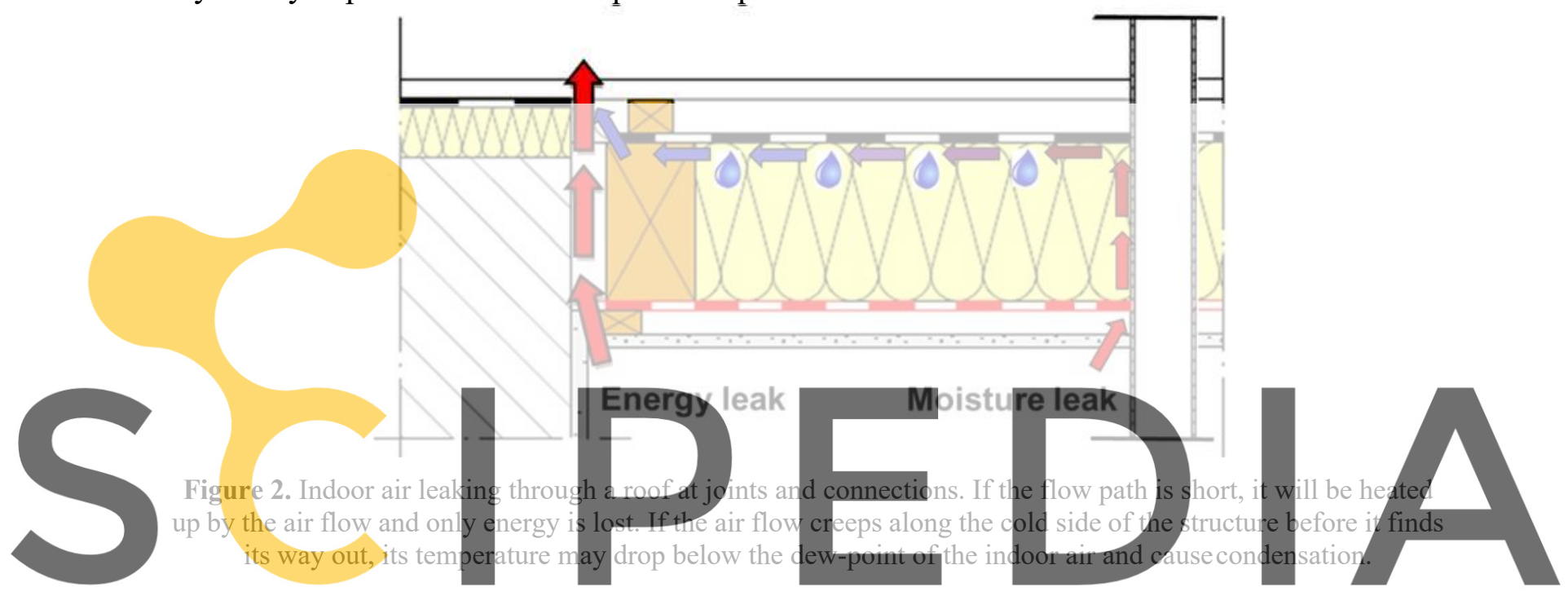

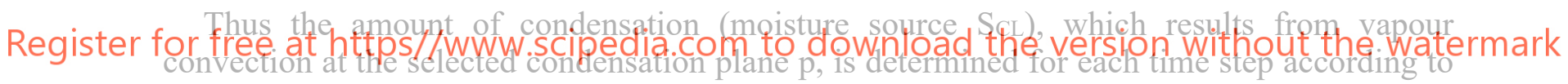
the following equation:

$$
\left.\left.S_{C L}=k_{C L} \cdot \underset{i}{(c-c}\right) \cdot(\underset{i}{s a t, p})+P_{e}\right)
$$

where $S_{C L} \quad$ moisture source due to vapour convection through the component $\left(\mathrm{kg} /\left(\mathrm{m}^{2} \mathrm{~h}\right)\right)$

$k_{C L} \quad$ air permeance of the "moisture leaks" of the component $\left(\mathrm{m}^{3} /\left(\mathrm{m}^{2} \cdot \mathrm{h} \cdot \mathrm{Pa}\right)\right)$

$c_{i} \quad$ water vapour concentration of the indoor air $\left(\mathrm{kg} / \mathrm{m}^{3}\right)$

$c_{\text {sat, } p} \quad$ water vapour saturation concentration at predefined plane $\mathrm{p}\left(\mathrm{kg} / \mathrm{m}^{3}\right)$

$P_{i}-P_{e} \quad$ air pressure difference over the considered envelope component $(\mathrm{Pa})$

The air pressure difference is assumed to be due to buoyancy effects and pressure differentials generated by ventilation systems. Wind pressure effects are disregarded because they are difficult to determine and do not act on the building envelope in a continuous manner. Based on investigations in Künzel et al. (2011) the air permeance of the moisture leaks is set to $1,9 \cdot 10-6 \mathrm{~m}^{3} /\left(\mathrm{m}^{2} \mathrm{~s} \cdot \mathrm{Pa}\right)\left[0,007 \mathrm{~m}^{3} /\left(\mathrm{m}^{2} \mathrm{~h} \cdot \mathrm{Pa}\right)\right]$ for envelope components installed according to best practice. Buildings with higher $\mathrm{k}_{\mathrm{CL}}$ would represent malpractice. Building components that can handle the moisture loads due to air convection are well-designed. Those that fail under these 
circumstances should either be redesigned or special care must be taken during installation which may include continuous moisture monitoring.

\subsection{New German Moisture Control Standard DIN 4108-3}

The current German moisture control standard for building envelope components DIN 4108-3 (2018) includes three assessment options. As first option, a designer may select a wall or roof assembly from a list of deemed to satisfy (DTS) constructions included in the standard. The second option, which may be applied, if the assembly to be designed, is not part of the DTS list represents the assessment by a steady-state dew-point calculation with fixed boundary conditions. However, there are a number of restrictions that have to be observed, e.g. green roofs, unvented metal roofs, capillary active interior insulation systems or basement assemblies must not be assessed.

Most importantly, options one and two may only be applied for envelope components of residential buildings or those that have a similar indoor climate (e.g. offices) without airconditioning. In all other cases option three applies, i.e. the designer has to perform a hygrothermal simulation according to appendix D of the standard. This appendix references EN 15026 and WTA 6-2 mentioned above as well as some other standards and guidelines dealing with the evaluation of hygrothermal simulation results, e.g. mould risk evaluation. A detailed flow chart showing the preconditions for selecting one of the options is depicted in figure 3 .

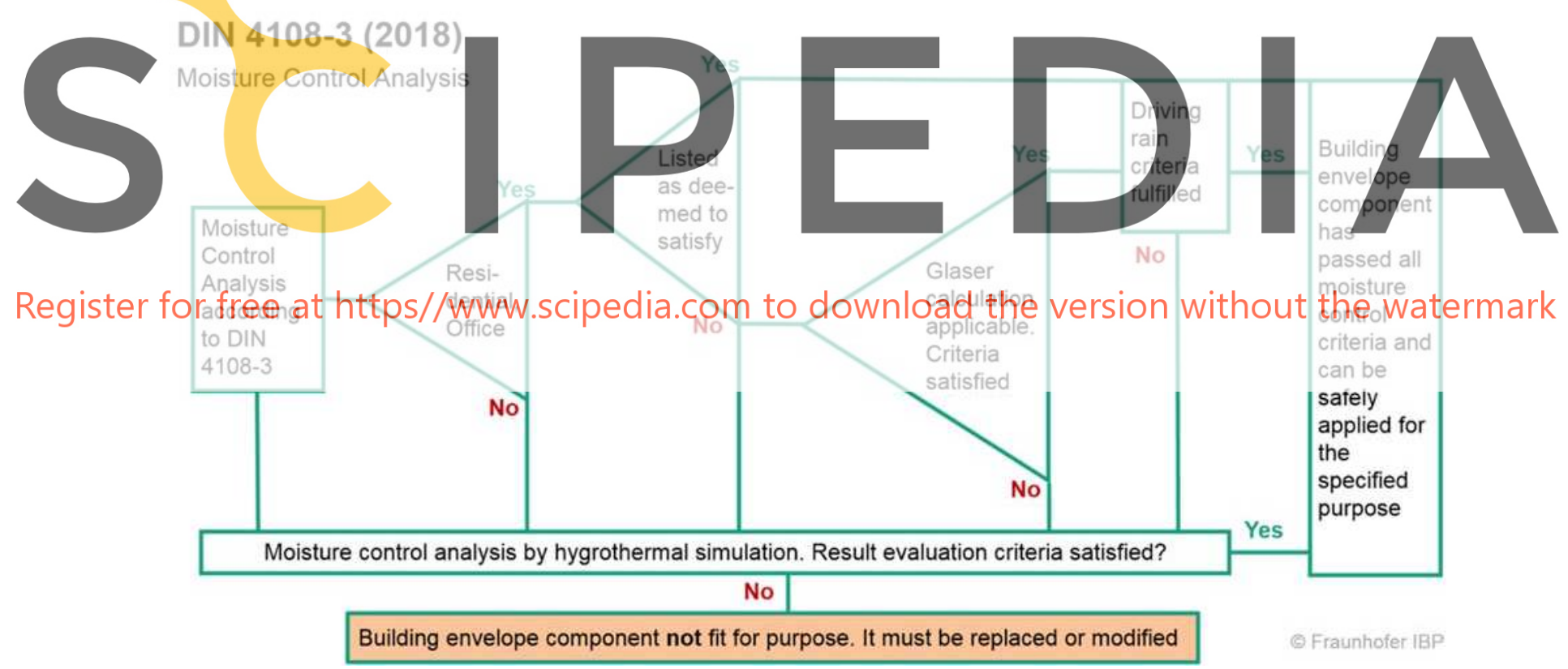

Figure 3. Flow chart explaining the preconditions for the moisture control assessment options in DIN 4108-3.

\section{Conclusions and Outlook}

Hygrothermal simulation models have become essential to advance our skills in sustainable and resilient building design. Practical experience has proven repeatedly that imperfections and small leakages in the building envelope are unavoidable and have to be accounted for. The same is true for material ageing and unexpected loads due to extreme weather conditions which will 
probably occur more frequently in the wake of climate change. The development of hygrothermal design models has to respond to these factors by searching for new approaches that are able to represent real life impacts and effects. This won't be possible without increased research efforts looking at the effects of leaks and other imperfections with the aim to quantify them for different construction types. Most importantly however, there has to be widespread discussions on what kind of flaws are acceptable in order to define what best practice workmanship actually means. Ultimately, the definition of unavoidable moisture sources will result in a clear discrimination between design and installation failures.

This task is far from being easy and may be very controversial because there is a lot of money involved in litigation cases. However, it also represents a great opportunity to arrive at better and more durable constructions and it is preferable, as well as much more sustainable to spend money on improving design instead of wasting money and resources on repair and excessive maintenance. International moisture control standards are slowly moving in the right direction by emphasizing the importance of hygrothermal simulation for realistic building component assessments. However, the next important step represents the integration of moisture control considerations already at the beginning of the design process. Until now, this is mostly done in the end when all components and HVAC systems are already specified leaving only minor options for modifications - e.g. selecting the permeance of vapour control or insulation layers.

In the future, the building dynamics (hygrothermal storage capacities of envelope components including HVAC systems) will become quintessential because of the more fluctuating renewable energy supply. This requires new building operation concepts and more integral design of the interdependent buid ding envelope and HVAC systems. Combinations of
both, such as thermally activated components of radiant interior surface heating and cooling
systems may be part of the response to the new challenges (see figure 4). Moisture control
design of such systems is way beyond simple dew-point calculations and may even require new
approaches for hygrothermal simulation models.

Register for freelatghttpeshdwWWariscipedia.6om to download the version without the watermark Building envelope and HVAC systems design must respond to local climate and building operation. They should not be sized independently but as integral part of a dynamic building design process.

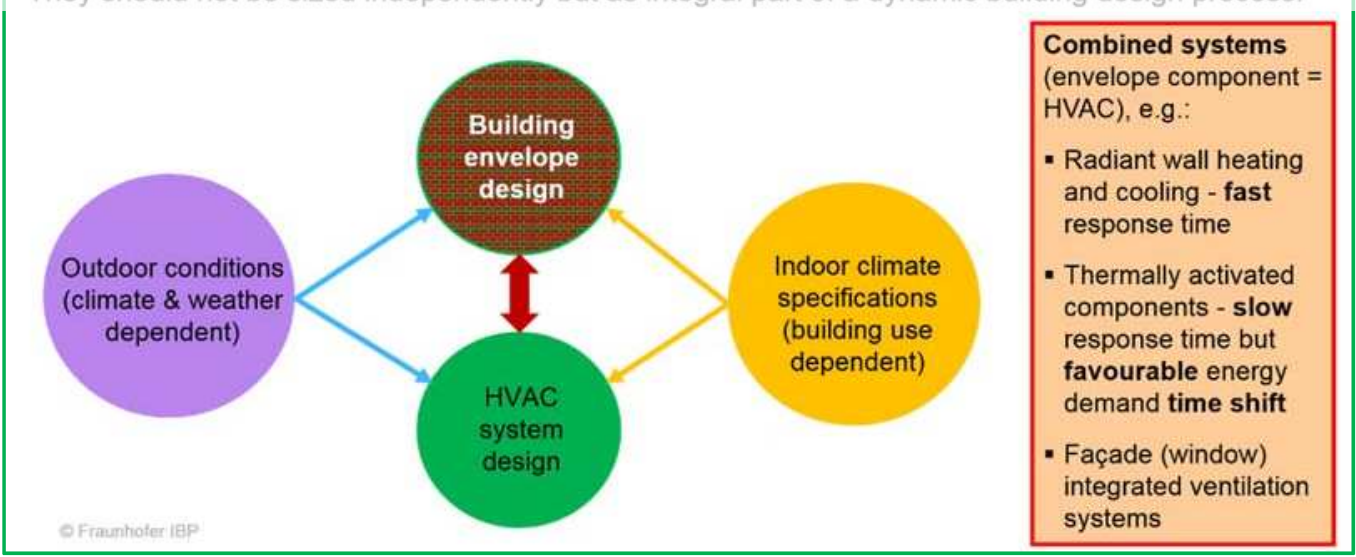

Figure 4. Appropriate design of building envelope and HVAC depends heavily on outdoor and indoor climate. Their performance is interdependent and increasingly both functions are combined in one system. 


\section{References}

ANSI/ASHRAE Standard 160 (2016). Criteria for Moisture Control Design Analysis in Buildings.

ASHRAE Handbook of Fundamentals (2017). Chapter 27 Heat, Air and Moisture Control in Building Assemblies - Examples.

Binder, A., Künzel, H.M. and Zirkelbach, D. (2013). A new approach to measure liquid transport in capillary active interior insulation. Proceedings 2nd Central European Symp. on Building Physics, TU Vienna, 393400.

Cheple, M. and Huelman, P. (2000). Literature Review of Exterior Insulation Finish. Systems and Stucco Finishes, Report MNDC/RP B80-0130, University of Minnesota.

Desjarlais, A.O., Karagiozis, A.N. and Aoki-Kramer, M. (2001). Wall Moisture Problems in Seattle. Buildings VIII proceedings, ASHRAE, 8.

DIN 4108-3 2018-10. Protection against moisture subject to climate conditions - Part 3: Requirements and directions for design and construction.

EN 15026 (2007). Hygrothermal performance of building components and building elements - Assessment of moisture transfer by numerical simulation.

Künzel, H.M. Zirkelbach D. and Schafaczek, B. (2011). Vanour control desion of wooden structures including moisture sources due to air exfiltration. Proceedings 9th Nordic Symposium on Building Physics (NSB), Tampere, 189-196.

TenWolde, A., Carll, C.G. and Malinauskas, V. (1998). Air Pressures in Wood Frame Walls. Thermal Performance of the Exterior Envelopes of Buildings VII. Clearwater, Florida, USA.

Van Den Bossche, N., Lacasse, M. and Janssens, A. (2011). Watertightness of Masonry Walls: An Overview. Proccedings $12 \mathrm{dbmc}$ Porto, 8.

WTA Guideline 6-2 (2014). Simulation of heat and moisture transfer.
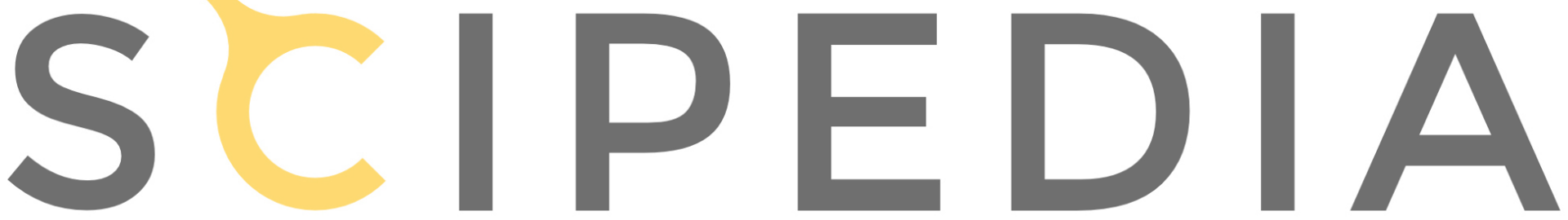

Register for free at https//www.scipedia.com to download the version without the watermark 